\title{
The Progress of Globalization and Educational Reforms in East Asia
}

\author{
SHIMBo, Atsuko*
}

The symposium entitled "Social Changes in East Asia and Educational reforms: China, Korea, and Singapore" suggested that these countries are carrying out rather drastic educational reforms in the context of rapid social changes. The knowledge gained from the symposium also has important suggestions for Japanese educational reform.

In addition, as a result of the discussions among the three panelists, common challenges in educational reforms in Asia emerged. These include, for example, the rise of the post-modern type meritocracy represented by learning ability and human power; the pursuit of excellence versus fairness and equality of education; the increase of poverty and deterioration of learning environments for children during economic recessions; and the improvement of teacher quality.

\section{Preface}

The symposium "Social Changes in East Asia and Educational reforms-China, Korea, and Singapore" was held at Tokyo University's Komaba campus on August 29, 2009. It was sponsored by the Japan Society for Study of Education, and guest speakers included: Dr. Chen Xiangming from China, Dr. Sung Youlkwan from South Korea, and Dr. Christine Lee from Singapore. The author of this paper was the discussant of the symposium. Comments and the guest speakers' responses to questions are summarized below.

\section{Educational Reforms in the Context of Social Changes: A Common Challenge}

Throughout the discussions with the three panelists, two points were particularly notable:

First, since the 1980s, there has been remarkable improvement in education in Asia, especially in regions that have been under the influence of Chinese culture.

For example, in China, there were millions of children who did not attend primary schools by the end of 1970 s. But primary and secondary education has expanded since then, and enroll-

\footnotetext{
* Waseda University

e-mail: akoba@waseda.jp
} 
ment rates at the primary and secondary level have reached nearly 100 percent today. In addition, the post-secondary enrollment rate reached 23 percent in 2007. The number of full-time college students has increased dramatically from $1,140,000$ in 1980 to $18,840,000$ in 2007. The size of post-secondary education in China, in terms of the number of students, has surpassed that of the United States and has become the largest in the world.

South Korea has entered an era of universal higher education, in which anybody who wishes to study in a college can enroll. Its post-secondary enrollment rate has exceeded 80 percent. Singapore has consistently ranked at or near the top in international achievement tests and is widely recognized as a country with world-class education quality.

In addition, accompanying the improvement of education capacity in regions under the influence of Chinese culture, and with the development of economic exchange, more and more students are crossing borders within the region to study. Academic exchange is actively taking place, helping countries on both sides to further improve their education quality. For example, the largest group of international students in China is from South Korea, and vice versa. As another example, the academic prestige of the National University of Singapore has been attracting top-tier students from China.

The second point is that all three countries, China, South Korea, and Singapore, are facing a turning point in the progress of globalization and are urged to adapt to a knowledge-based society. Also, those countries are deeply impacted by the severe global recession taking place after the shock of the collapse of Lehman Brothers in 2008. University graduates in those countries have had a difficult time in finding jobs, young workers are unable to receive decent incomes (the socalled "working poor"), and child poverty is increasing. In this kind of situation, "educational reforms in the context of social changes" become a common challenge, not only for China, South Korea, and Singapore, but also for Japan.

Therefore, the directions shown in the educational reforms in all these countries have many similarities. For example: China focuses on "character education" which emphasizes the potential ability to learn; South Korea promotes life-learning ability; Singapore encourages self-learning; and Japan values self-motivated learners and thinkers. The goals set in the reforms are not to simply cram knowledge to students, but to nurture their ability to learn so that they can continue to improve themselves throughout their lives.

\section{Reforms by Country}

In this section, each country's report is summarized in the order of presentation during the symposium: Singapore, Korea, and China.

\section{(1) Singapore}

Based on the author's understanding, the background of Singapore's educational reform is as follows. First, Singapore's educational reform seems to be backed by its citizens' strong will to build the nation with education as its foundation. For a small country with limited natural resources, education is the only way for Singapore to maintain its competitive edge. Second, although Singapore has been noted for its high quality of school education, there are few internationallyrecognized scientists, researchers, or entrepreneurs. Third, Singapore needs educational reform to transform the country so that it can adapt to a "knowledge-based economy." 
In her presentation at the symposium, Dr. Lee introduced the rationale of Singapore's educational reform, which emphasizes the nurturing of creative and innovative life-long learners. Singapore is turning away from traditional curriculum-centered teaching methods and is implementing a variety of measures to improve teaching/learning in the classroom.

Based on Dr. Lee's presentation, I noticed that Singapore's educational reform focuses on curriculum and teaching methods, two of the most important aspects of education.

The author of this report raised two questions following Dr. Lee's presentation. First, why do many Singaporean students enjoy studying science and mathematics and score high on international achievement tests? Why do Singaporean students remain highly motivated in spite of the implementation of a comprehensive school tracking system?

While the ratio of students who like science and mathematics is low in both Japan and South Korea, despite their relatively high scores in international achievement tests, Singapore students have strong interest in these subjects and also score very high on these tests.

In addition, Singapore has a system called, a "streaming system", in which students are divided into different streams based on academic performance. Based on the results of the elementary school completion exam, they are put into the special course, the express course, and the normal course at the secondary level. The course of study also decides the course of life taken after secondary education. From Japan's viewpoint, it is intriguing to understand how students can keep highly motivated in spite of the thorough implementation of such a tracking system.

Dr. Lee asserted that students remain motivated because the principle of meritocracy is working in a positive way. The system assures students that if they work hard, they can enter good schools and get good jobs.

The second question concerned the Institute of Technical Education (ITE), a technical education school that serves academically underprivileged students. Sim (2009) argues that if the educational aspirations of ITE students are high, they become motivated after they enter the school, and they hope to continue their education at an even higher level. In other words, these students' educational aspirations are rekindled. The author was curious to know how this could have happened.

Dr. Lee responded that the government provides substantial financial assistance for all education institutions, including the ITE. The ITE campus is beautiful, and even more attractive than the Komaba campus of Tokyo University, where the symposium was held. It enables ITE students to feel that they are well taken care of. Dr. Lee's comments made the author realize that in order to foster the growth of future generations, it is important to recognize all students as equally valuable, and that it is necessary to have a sufficient education budget to realize this ideal.

In addition, the author of this paper asked about how reform of the teacher system has been conducted as a concrete measure to reform educational methods known as "Teach Less, Learn More (2004-2005)." Dr. Lee replied that the most difficult thing happening in the course of educational reform is changing teachers' ways of thinking, and in this sense, the arguments put forth by Dr. Chen Xiangming can be considered meaningful.

\section{(2) South Korea}

In South Korea, the senior high school standardization policy was introduced in 1973. This policy aimed to offer equal education opportunities widely up until the senior high school level. The policy would automatically distribute students who had passed the regular senior high school entrance exams to senior high schools within districts by a lottery. Although the lack of choice was 
a problem, this policy resulted in relaxing of the heightened competition in senior high school entrance exams.

As a result, however, competition in university entrance exams became fiercer, and it has led to the prosperity of prep schools and to an increase in private education expenditures due to parents and students' beliefs that they could not solely depend on public education.

Kim Yeongsam's civilian administration came into power in 1993, and in May 1995, the Presidential Commission on Educational Reform (1995) introduced a report produced by Kim Kim Yeongsam government that had as its goal the establishment of a new education system that would lead to an age of globalization and information technology. Since then, educational reforms in South Korea have been guided by neoliberalism. More specifically, these reforms have included the diversification of schools through structural adjustments and deregulation, the expansion of the discretionary authority of school principals, the reduction of waste in educational funding, the expansion of choices for education consumers and the thorough implementation of the principle of competition, and the transfer of government responsibilities for public education to private sectors, which has resulted in the increase of private educational spending and a crisis for public education.

In consideration of these educational reforms, Dr. Sung presented three points in his report. (1) The borrowing of educational ideology and terminology from the U.S. and the U.K.. (2) By promoting the concepts of choice and diversity, educational reform reports in and after 1995 actually facilitated the sorting and hierarchization of schools and students, as well as the collapse of the high school level equalization policy. (3) An increase in choice has led to an increase in the number of elite schools. Although South Korea is ranked among the top in international achievement tests, students are constantly under huge pressure to enter an elite school.

Dr. Sung's report has strengthened the author's opinion that South Korea's educational reform has much in common with Japan. For example, Korea's reform is based on neoliberalism. In South Korea, although the college enrollment rate was 83.8 percent in 2008 (the highest in the world), job shortages for college graduates due to the economic crises in 1997 and 2008 have become a big issue that may in fact lead to social instability. The author asked Dr. Sung about what kinds of measures will be taken to address this issue. Dr. Sung responded that there are various opinions regarding the capacity reduction of colleges, and support to students in their job hunting efforts is provided in forms such as internships.

The author further inquired about measures taken to alleviate social inequality through education, both from policy and practical perspectives. According to Dr. Sung, measures such as an education and/or a welfare subsidy program for children and a free lunch program have been adopted to cope with child poverty under the Democratic administration. However, under the Lee Myungbak government, education policies have favored elitism and scholastic ability, and the focus of education assistance for poor children has shifted from welfare to academic improvement. Dr. Sung himself participates in activities teaching children in poor areas two hours a week.

Moreover, in South Korea, university faculty issued the "Declaration of the situation" in 2009 to oppose the educational policy of the Lee administration, which was also signed by Dr. Sung. Teacher's unions supported the declaration. Although university faculty members were not affected, 88 teachers from the teacher's union were given job dismissals by the federal government. The union is planning to bring this controversy to court. South Korea was ruled by a military regime for a long period, and though a civilian government was finally established as a result of people's efforts, the struggle for democratization is still going on even today. 


\section{(3) China}

The report by Dr. Chen examines the theorization of teachers' practical experience. In order to properly place this report in the context of Chinese educational reform and teacher training, I would like to provide a brief introduction to educational reform in China and its teachers' status based on my understanding.

First of all, accompanying improved enrollment rates at all school levels, Chinese education has entered a stage of qualitative improvement, in addition to its quantitative expansion. Second, when attempting to improve the quality of education, inadequate teacher quality has become an issue, especially in rural villages. This is one of the factors that has led to regional educational disparities in China.

Third, one traditional Chinese teaching methods has been a recitation of textbooks, and it should be noted that. this remains a major teaching method today. Fourth, historically, Chinese teachers, especially elementary school teachers, had low social status and prestige, and they received low salaries.

Lastly, in order to adapt to the pressures of globalization, basic educational curriculum reform outlines were promulgated in 2001. This is a guideline of the basic education curriculum reform for the first ten years in the 21 st century. Some of the key points include changing from education for school entrance exams to "character education", developing integrated curriculum, compiling and diversifying textbooks, introducing integrated practicum, and the introduction of a foreign language (English) starting in the third grade in elementary schools.

In her report, Dr. Chen recognized the knowledge that teachers have as "practical knowledge" and explained the theoretical validity of the practical knowledge concept. Teachers should, as we conventionally believe, neither lack knowledge nor be simply consumers of knowledge. Dr. Chen's argument empowers teachers and is a critical study for teachers.

The first question from the author for Dr. Chen was about the quality of rural village teachers. This is because child poverty was one of the common issues raised in the symposium. The poor quality of teachers in rural villages is thought to cause urban-rural education inequalities, and it further leads to a perpetual discrepancy by education. In addition, Dr. Chen has substantial indepth experience with rural education. She is a director of the "Sino-British Basic Education Project," which was largely implemented in poor rural villages in the Gansu Province and supported by the U.K.

Dr. Chen's answer was that the educational problem in China was rooted in the low salary level and low quality of part-time teachers. To address the issue, teachers are dispatched from cities to villages with special benefits in salary, housing, and education for their children. Also, tuition is exempted for normal university students in exchange for 10 years of teaching in rural villages after graduation.

The author then asked Dr. Chen about the implementation of practical knowledge in rural agricultural areas. There are motivated teachers in rural villages, but the reality is that the skills/ knowledge learned through teacher training cannot be successfully applied to schools in rural villages. In other words, practical knowledge cannot be developed. Therefore, the author asked Dr. Chen how we could overcome these difficult circumstances.

According to the author's interview survey targeting rural teachers in China that was conducted in 2007, even though teachers participate in teacher training and learn new teaching methods, such as group activities, it is difficult in reality to apply these methods in classrooms, as principals and parents criticize such activities as playing rather than learning. 
Dr. Chen responded that because of city parents' high expectations for their children to get into better schools, teachers in urban schools are under pressure to improve students' test scores, and thus it is difficult to change their way of thinking. Rural teachers, by comparison, have more flexibility.

As a supplementary explanation, Dr. Chen added that in order to reform education in China, it is necessary to diversify the procedures for college admission, such as the introduction of a recommendation system. However, such changes may also create problems, such as backdoor admission. Furthermore, the inputting-knowledge type of education actually gives rural students more chances of entering a college. Changes to the college entrance examination may actually pose a larger challenge to rural students than to urban students. The reform is complicated and it is not easy to find a single appropriate solution.

\section{Conclusion}

As a whole, the symposium demonstrated that countries such as Singapore, South Korea, and China are carrying out drastic educational reforms in the context of rapid social changes. The knowledge gained from the symposium also has important suggestions for Japanese education.

In addition, through the discussions among the three panelists, common challenges in educational reforms in Asia have emerged. These include, for example, the rise of the post-modern type meritocracy as represented by learning ability and human power, the pursuit of excellence versus fairness and equality of education, the increase in poverty and deterioration of learning environments for children during economic recessions, and the improvement of teacher quality.

The author eagerly hopes that academic research exchange advances in the future on the basis of this symposium.

\section{References}

Arita, Shin., Education and Social Stratification in Korea, University of Tokyo Press, Tokyo, 2006

Makino, Atsushi., Social Change and Education in Contemporary China, Keiso Shobou, Tokyo, 2006

Minami, Ryoshin., Makino, Fumio., and Luo Huangzhen, Education and Economic Development in China, Toyo Keizai Inc., Tokyo, 2008

Sim, Choonkiat., A Sociological Study on the Educational System and Meritocracy of Singapore, Toyokan Publishing Co., Ltd., Tokyo, 2009 